\title{
La mirada como acto político. El cine y otros audiovisuales como herramientas educativas de (re)construcción del mundo
}

\author{
The gaze as a political act. Cinema and other audiovisuals as \\ educational tools for (re)constructing the world
}

Carlos ESCAÑO. Universidad de Sevilla (España). jcescano@us.es

Resumen: El presente artículo propone una reflexión sobre la mirada y lo visual como constituyentes y constructores de realidad cultural. Un estudio articulado a través del análisis cultural de ideas y conceptos claves como método de reflexión. La construcción de la realidad siempre ha sido un hecho político dirigido por los poderes fácticos, pero al entrar en juego, desde el siglo pasado, el potencial de la creación audiovisual y digital para generar mundos posibles, la situación ha mutado hacia un contexto donde la creación y colonización de mundos visuales (y por lo tanto, reales) es prioritaria para las estrategias políticas. Se propone tal fenómeno cultural como un hecho eminentemente ideológico: la mirada cobra una especial relevancia en un cosmos mediado por la imagen, el audiovisual, lo digital, a través de sus dispositivos. El mirar (el mundo), más que nunca, es un hecho político; la producción de imágenes generadas a través múltiples dispositivos se erige como el principal acto en la construcción de la mirada personal y colectiva. La construcción de imágenes depende de esa maquinaria (ideológica) de dispositivos e instrumentos dispuesta para su configuración, la política de generación de imágenes y la usabilidad de tales dispositivos, así como la producción icónica en sí. La mirada y su construcción mantienen profundas implicaciones pedagógicas, donde la imagen en movimiento deviene en poderoso instrumento de transformación educativa $y$, por extensión, social.

Palabras clave: mirada, cine, ideología, hegemonía cultural, educación visual.

Abstract: This article proposes a reflection on the gaze and the visual as constituents
and constructors of cultural reality. A study articulated through the cultural analysis
of ideas and key concepts as a method of reflection. The construction of reality has 
always been a political fact directed by the factual powers, but when the potential of audiovisual and digital creation to generate possible worlds comes into play since the last century, the situation has mutated towards a context where the creation and colonization of visual (and therefore real) worlds is a priority for political strategies. Such a cultural phenomenon is proposed as an eminently ideological fact: the gaze takes on special relevance in a cosmos mediated by the image, the audiovisual, the digital, through its devices. The gaze (on the world), more than ever, is a political fact; the production of images generated through multiple devices stands as the main act in the construction of the personal and collective gaze. The construction of images depends on that (ideological) machinery of devices and instruments arranged for their configuration, the politics of image generation and the usability of such devices, as well as the iconic production itself. The gaze and its construction maintain profound pedagogical implications, where the moving image becomes a powerful instrument of educational and, by extension, social transformation.

Keywords: gaze, cinema, audiovisuals, ideology, cultural hegemony, visual education.

\section{Introducción: lo único sagrado es la ilusión}

Has preferido ser un loco, una minoría de uno solo. Convéncete, Winston; solamente el espíritu disciplinado puede ver la realidad. Crees que la realidad es algo objetivo, externo, que existe por derecho propio. Crees también que la naturaleza de la realidad se demuestra por sí misma. Cuando te engañas a ti mismo pensando que ves algo, das por cierto que todos los demás están viendo lo mismo que tú. Pero te aseguro, Winston, que la realidad no es externa. La realidad existe en la mente humana y en ningún otro sitio. (Orwell, 1980, p. 120)

En el inicio de La société du spectacle (La sociedad del espectáculo) Guy Debord (2000) recogía las siguientes palabras de Ludwig Feuerbach: "Nuestra época, sin duda, prefiere la imagen a la cosa, la copia al original, la representación a la realidad, la apariencia al ser... Para ella, lo único sagrado es la ilusión, mientras que lo profano es la verdad. Es más, lo sagrado se engrandece a sus ojos a medida que disminuye la verdad y aumenta la ilusión, tanto que el colmo de la ilusión es para ella el colmo de lo sagrado". Guy Debord utilizaba esta cita para arrancar su capítulo número uno, La separación perfecta, de su afamado y referencial texto. Renglón seguido, Debord sentencia que todo lo directamente experimentado se ha convertido en una representación. El filósofo (y revolucionario) francés lo dejó escrito ya en el año 1967, y la cita de Feuerbach corresponde a su texto Das Wesen des Christentums (La esencia del cristianismo) que fue publicado por primera vez en 1841. Más de medio siglo ha transcurrido desde el primero y mucho más de siglo y medio en relación con el segundo. Una reflexión secular que no solo mantiene su pertinencia, sino que se muestra más inspiradora si cabe. Feuerbach y Debord fueron en sus tiempos agudos psicólogos de nuestra realidad, y si entonces alertaban de la situación de sus presentes, hoy probablemente advertirían cómo esa maquinaria de ilusión icónica 
y espectacular conforma y modela hasta nuestra realidad más íntima. Feuerbach centraba su trabajo en una cŕitica al contexto religioso y en cómo el ser humano se ha proyectado en la idea de Dios, y cómo los atributos humanos fueron asociados con los de un ente sobrenatural y abstracto: una representación de la realidad que se torna esencialmente ilusoria, pero que a su vez determina la realidad en sí. Guy Debord extrapolaba tal proyección con lo que directamente sucede en nuestra realidad espectacularizada: "El espectáculo no es un conjunto de imágenes sino una relación social entre las personas mediatizada por las imágenes" (Debord, 2000, p. 38), una sociedad alienada por el mundo icónico que nos rodea. Si cruzamos los dos puntos de vista críticos de tales autores, hoy esos tintes espectaculares se han tornado divinos, y la realidad mediática y mediatizada, es decir, nuestra realidad cotidiana ya sin distinción dicotómica entre mundo ilusorio-mundo real- es creada cultural y socialmente, sin impunidad, por demiurgos mediáticos que implementan órdenes y voluntades políticas específicas nada azarosas. La construcción de la realidad siempre ha sido un hecho político dirigido por los poderes fácticos, pero al entrar en juego, desde el siglo pasado, el potencial de la creación audiovisual y digital para generar mundos posibles — esencialmente a través de la imagen_-, la situación ha mutado hacia un contexto icónico casi mágico donde la creación y colonización de mundos visuales y audiovisuales (y por lo tanto, reales) es prioritaria para las estrategias políticas, donde la práctica ideológica del gran hermano de Orwell cuando aludía a que la objetividad no es algo externo que existe por derecho propio y por su naturaleza en sí- demuestra que aquel imposible dos más dos igual a cinco, extraído de su celebérrima novela, no solo es algo factible, sino un hecho fehaciente en nuestra contemporaneidad. Esa construcción mediática implica admitir que la mirada es una acción cultural, una construcción que a su vez implica asumir que la articulación simbólica y colectiva es un juego de subordinación de poderes, un juego ideológico. La mirada cobra una especial relevancia en un cosmos mediado por la imagen, el audiovisual, lo digital, a través de sus dispositivos. El mirar (el mundo), más que nunca, es un hecho político.

En este sentido, profundizaremos dentro del recorrido de estas líneas, a partir de dos reflexiones que desarrollan ideas ya latentes en esta introducción, y que aluden a aquello que implica y provoca la mirada en la construcción de la realidad, a la manera en que la articulamos y bajo qué principios. 


\section{¿Qué implica y provoca la mirada en la construcción de la realidad?}

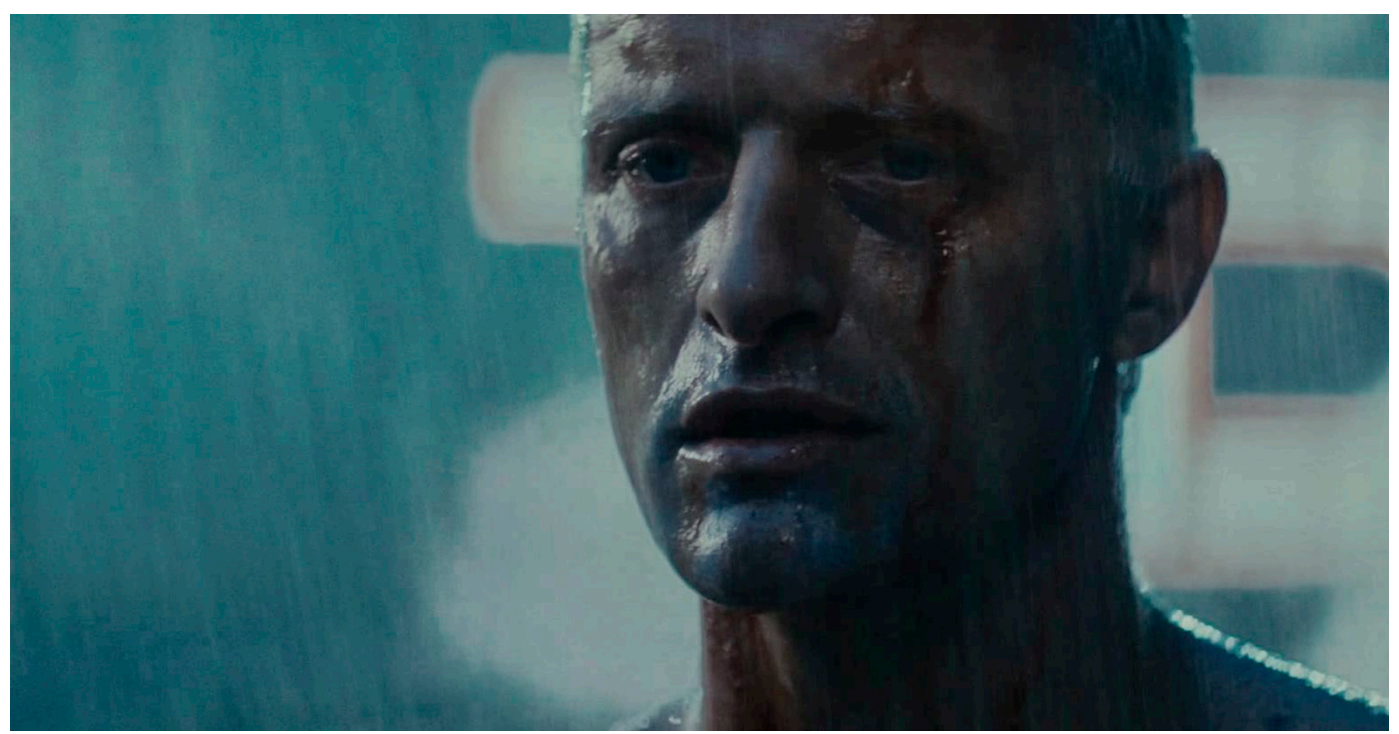

Figura 1. Fotograma de la película Blade Runner. Fuente: Película Blade Runner (Scott, 1982), imagen procedente de https://democresia.es/democultura/las-lagrimas-roy-batty/

Yo he visto cosas que vosotros no creeríais. Atacar naves en llamas más allá de Orión. He visto Rayos-C brillar en la oscuridad, cerca de la puerta de Tannhäuser. Todos esos momentos se perderán en el tiempo como lágrimas en la lluvia. Roy Batty, nexus 6. Blade Runner. (Scott, 1982)

Mirar es construir (la) realidad. Lo que no sea contemplado se perderá como lágrimas en la lluvia. Lo que no sea acogido bajo la hegemonía cultural opera más allá de los márgenes. Ese más allá es socialmente inexistente. Esa hegemonía es ocularcentrista desde el occidente cultural. Momentos que se pierden fuera de los límites temporales geoculturales y digitales, porque la construcción de la realidad es interacción entre el ojo y el fenómeno. Entre el ojo de ayer y el ojo de hoy. Entre el ojo y los ojos. Entre los ojos y los ojos. Entre los ojos y el fenómeno.

Desencriptemos la idea acabada de plantear. La construcción de la realidad es una interacción entre el ojo y el fenómeno, es decir, se apunta así a la relación entre el sujeto que contempla lo externo al sujeto y el acontecimiento fuera de las fronteras del yo - suponiendo este afuera como premisa-. Conformando de esta manera el mundo: dando forma - desde un sentido estético kantiano - a un cosmos informe de espacio y tiempo sensibles, necesitados de un ojo para poder ser articulado.

Entre el ojo de ayer y el ojo de hoy, es decir, entre el sujeto - interactuante entre sí mismo y lo dado - que negocia significados, en el presente, información no solo actual, sino la procedente de su pasado, de su mochila cultural: dando sentido a esa contemplación poniendo en juego los saberes adquiridos, símbolos y lenguajes que navegan entre esos saberes sobre la naturaleza, la cultura y la sociedad. 
Entre el ojo y los ojos: entre el yo y el vosotros y el ellos, una interacción entre el sujeto y la pluralidad de sujetos. Decía Berger (2017) que "poco después de ver, nos damos cuenta de que también podemos ser vistos. El ojo del otro se combina con el nuestro para dar plena credibilidad al hecho de que formamos parte del mundo visible" (p. 9). En este tejido donde habita el mirar y el ser mirado, el mirar subjetivo con el mirar colectivo, se entrelaza una red de interpretaciones que recrean símbolos y lenguajes para continuar conformando en el mismo presente y en un futuro otras interpretaciones entre todos y todas. No existe el lenguaje si no es en comunidad. No existen los símbolos si no son en comunidad.

Es por ello que de manera inevitable se necesita la pluralidad para la construcción de la realidad, de las realidades: entre los ojos y los ojos. Entre la pluralidad que interacciona con la misma pluralidad, no solo con el sujeto que contempla, sino con la propia red de interpretaciones.

Y todo en un bucle que siempre es condicionante entre los ojos de la pluralidad que, de nuevo, finalmente, incide en otros fenómenos: entre los ojos y el fenómeno.

Así, la realidad se articula como hecho - en espacio y tiempo - intersubjetivo, donde el ojo, como la gran puerta sensorial del vigente occidente cultural, se convierte en el canal político con más fuerza social. El ojo como dispositivo político, como entidad configuradora, discriminadora, seleccionadora y organizadora de nuestras realidades, de nuestro yo, de nuestro pensamiento. La visión mantiene así la gran virtud que consiste "no solo en que se trata de un medio altamente sofisticado, sino en que su universo ofrece una información inagotablemente rica sobre los objetos y los acontecimientos del mundo exterior. Por tanto, la visión es el medio primordial del pensamiento" (Arnheim, 1986, p. 32).

La construcción de la mirada es un acto sociocultural condicionado, en consecuencia, por decisiones individuales, colectivas y las relaciones de poder entre sí. Siguiendo este argumento, la construcción de la mirada (por ende, construcción de la realidad) constituirá un hecho ideológico. Ideología como forma en que el significado sirve para sustentar las relaciones de dominio, noción que utiliza Terry Eagleton, apoyándose en John B. Thompson (1984), señalando que la ideología no solo hace alusión a un sistema de creencias sino que "quizá la respuesta más general es que la ideología tiene que ver con la legitimación del poder de un grupo o clase social dominante" (Eagleton, 1997, p. 24).

A partir de este enfoque podríamos estar en situación de enunciar que el cómo vemos, es decir, nuestro sistema representacional de la visión, incluyendo el acto de ver y los mecanismos para representar la mirada, es ya per sé una ideología. Para desarrollar esta idea es oportuna la teoría que Jacques Aumont (1992) trazaba sobre la visión, la imagen y la visualidad. Aumont distinguía tres fases analíticas para explicar la configuración de la mirada: en primer lugar, el análisis realizado 
en torno al funcionamiento del ojo, atendiendo a lo visible (donde analizaba el ojo y los elementos perceptivos); en segundo lugar, el análisis del paso de los visible a lo visual: siguiendo el pensamiento del autor, hay un paso perceptivo sensible a lo perceptivo espacial y temporal que implica una acción sensorial más articulada aún, donde lo táctil y lo cinético se relacionan con el cuerpo más allá del órgano óptico, y por lo tanto implica una acción psicológica más complicada; en tercer y último lugar, el análisis de lo visual a lo imaginario, contexto que queda atravesado por la interpretación y donde se puede ya ubicar la idea de mirada: una acción compleja que abandona la esfera de lo puramente visual, la mirada como "lo que define la intencionalidad y la finalidad de la visión" (Aumont, 1992, p. 62). Aunque autores como Arnheim apuntan al papel activo del pensamiento en el hecho perceptivo sensible - $-\mathrm{y}$, por lo tanto, nunca existirá una fase pasiva ni maquinal en la acción perceptiva-, la teoría desarrollada por Aumont, sirve para señalar de manera aclaratoria que el hecho visual, culminado en la configuración de la mirada en el sujeto, implica una trayectoria psicológica donde la intencionalidad, la interpretación y la finalidad de la misma adquiere una relevancia en su constitución. Toda intencionalidad e interpretación están sujetas a convenciones culturales y voluntad subjetiva. Toda acción interpretativa estará subyugada a los valores propios de un contexto, así, interpretamos igualmente que el mirar, desde un punto de vista fisiológico-óptico hasta su culminación interpretativa, incluye los factores de atención, discriminación y selección que están mediados por principios psicológicos y neurofísicos influidos a su vez por las emociones, sentimientos, saberes y múltiples aspectos culturales y sociales: ante esta situación el hecho de ver como el ser humano contempla (en tres dimensiones, con una determinada escala cromática derivada de longitudes de onda concretas de la luz, con un sistema cercano a la perspectiva cónica, etc.) es ya parte constituyente de una ideología. Si nuestra mirada estuviera mediada por la bidimensionalidad, o un monocromatismo, o se asemejara a otros sistemas de representación geométrica descriptiva como el sistema diédrico o el sistema axonométrico, nuestras respuestas sociales y culturales serían radicalmente distintas, sería otro orden cotidiano y social para nuestra vida: implicaría otro hábitat, otras profesiones, otro ocio, otras relaciones sociales, otras artes, otra ciencia, otros medios de producción y convivencia. Otra ideología. Otra política. 
¿Qué tipo de política implementamos para articular la mirada?

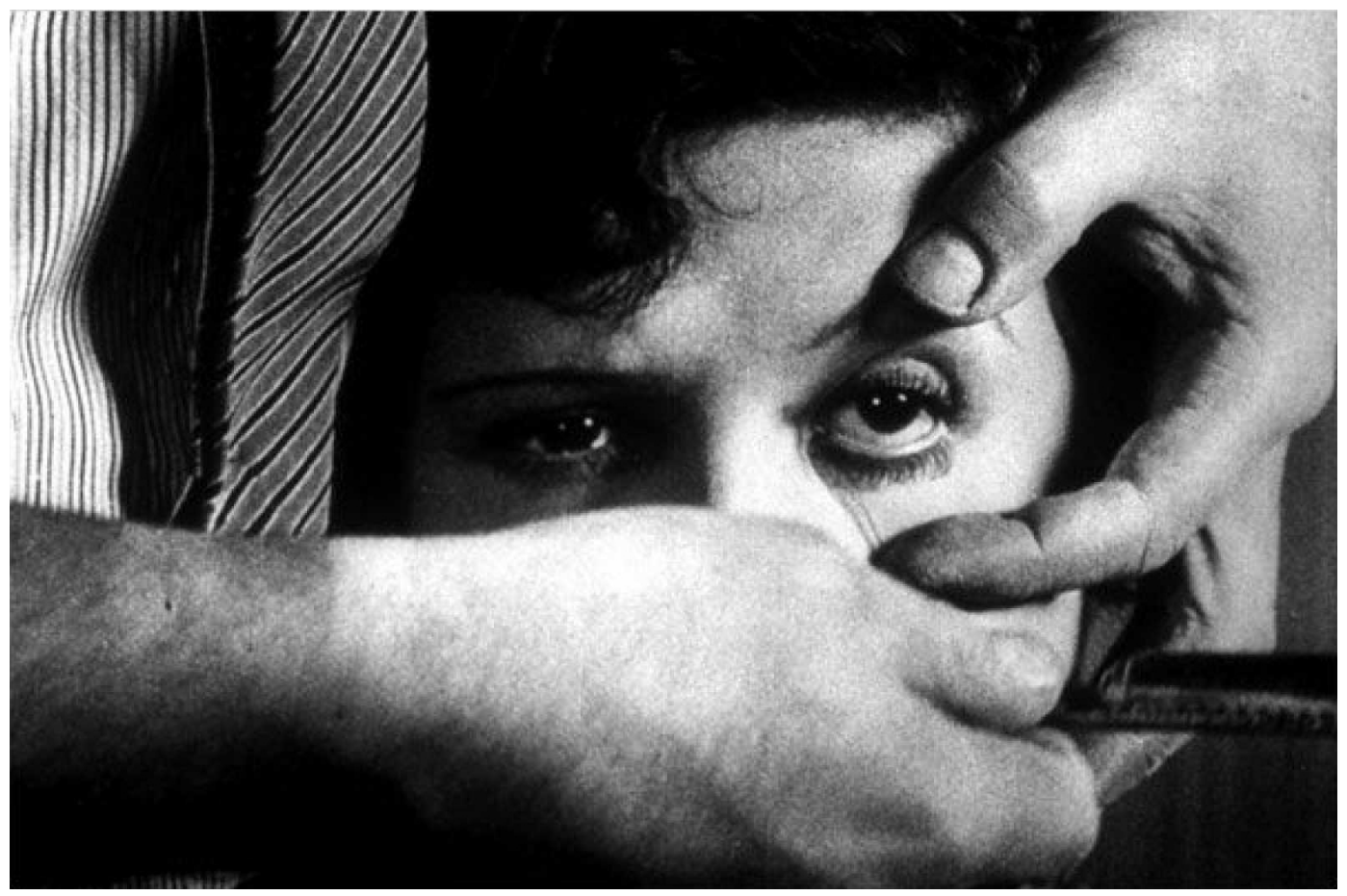

Figura 2. Fotograma de la película Un perro andaluz. Fuente: Película Un perro andaluz (Buñuel, 1929), imagen procedente de http://www.rtve.es/alacarta/videos/un-perro-andaluz/perroandaluz/1570997/

"Si hay imágenes, es que tenemos ojos" (Aumont, 1992, p. 17). Si tenemos ojos — respondiendo de manera tautológica-, es que somos creadores de imágenes. Si creamos imágenes, construimos mundo. Esta es la secuencia, en un principio sencilla, que nos indica la ruta hacia el tipo de acción política que necesitamos como ciudadanía: la construcción de la realidad bajo un punto de vista democrático y diverso, respondiendo a la propia naturaleza de la imagen que no puede constituirse como territorio autónomo y clausurado sin comunicación con lo que le rodea, está inserta en los múltiples movimientos de significación en el interior de las sociedades, desde el instante en que la cultura se apodera de ella, ubicada en la mente de los múltiples y muy diversos creadores de imágenes, el texto icónico se ofrece a los efectos de la figura y el discurso (Mettz, 1972). Todo el conjunto social, todos los agentes implicados en el desarrollo social y cultural de nuestra comunidad, mantenemos una grave responsabilidad en la construcción de la mirada colectiva. Cuando se subraya el concepto de mirada colectiva estamos tratando una idea compleja que hace referencia a la manera de visualizar y visualizarse que mantenemos como sociedad, y ello implica conceptos e instrumentos para llevarla a cabo. ¿Cómo se construye la mirada? El principal dispositivo para la construcción de imágenes es el ojo, no cabe duda, pero la política con la que generamos esas imágenes va más allá de una acción fisiológica, tal y como hemos reflexionado anteriormente. Como parte de los mecanismos pedagógicos de la mirada (eufemismo para referirnos a los mecanismos aleccionadores, de control y, 
en definitiva, de domesticación), la sociedad contemporánea apela a intermediarios protésicos, dispositivos de reproducción de la misma y a extensiones mediáticas oculares, en el sentido que McLuhan definía a los medios: desde los instrumentos y materiales visuales y plásticos, con sus procedimientos básicos de representación e invención de realidad en siglos anteriores, hasta la máquina fotográfica, el cinematógrafo, la cámara videográfica o los dispositivos digitales contemporáneos, así como sus correspondientes canales de difusión (espacios analógicos y digitales, cines, videojuegos, televisiones e Internet). Instrumentos que están atravesados igualmente por una acción ideológica (Aumont, 1992), que nos facultan para la creación, gestión y difusión de imágenes, para la generación de una interfaz cultural entre el yo y el mundo externo, conformándose en última instancia un híbrido entre mundos internos y externos. Una interfaz que se convierte en realidad habitada. Explicado en palabras de Nelson Goodman un mundo compuesto de otros mundos:

Las muchas estofas de las que están hechos los mundos - la materia, la energía, las ondas, los fenómenos- están hechas a la vez que esos mismos mundos. ¿Pero de qué están hechas, a su vez, tales estofas? No están hechas, evidentemente, de la nada, sino que están hechas de otros mundos. La construcción de mundos, tal como la conocemos, parte siempre de mundos preexistentes de manera que hacer es, así, rehacer. (Goodman, 2013, p. 24)

Así, la producción de imágenes generadas y organizadas a través de tal interfazmundo se erige como el principal hecho en la construcción de la mirada personal y colectiva. La construcción de imágenes depende de esa maquinaria (ideológica) de dispositivos dispuesta para su configuración, y de la política de generación de imágenes y la usabilidad de tales dispositivos, además de la propia producción icónica en sí. Ante la responsabilidad de producción y uso no todos somos iguales. Unos mantienen el poder y otros un contrapoder, algunos pueden construir miradas y otros además tienen el poder de cercenarlas con navajas políticas. Somos conscientes de que "nunca miramos solo una cosa; siempre miramos la relación entre las cosas y nosotros mismos" (Berger, 2017, p. 9), y nuestro mirar se convierte en un hacernos, nuestra producción nos implica a todos, aunque medios y quienes ostentan su poder prescriben con facilidad relaciones entre cosas y sujetos, procurando realidades orquestadas y dirigidas. Dentro de esta estrategia mediática (de generación de interfaz-mundo-realidad), el audiovisual, que es la dimensión visual con el grado de iconicidad más elevada (por debajo de la representación tridimensional), extendida y aceptada en su uso mediático, se convierte así en uno de los instrumentos de orquestación (propaganda o creación de realidades) más eficaces. La naturaleza del cine (como subgénero dentro de la dimensión audiovisual) y otros audiovisuales (hoy en su gran oferta digital) inducen y promueven nuestras realidades:

El cine, como otros fragmentos del discurso social, pone en escena un modo de pensar lo real. Sin embargo, la noción misma de "realidad" es inseparable de su producción en el interior de la semiosis. Este concepto, que proviene de Peirce, debe entenderse como el proceso por el cual la realidad social funciona como punto de partida de la producción de un sentido posible acerca de lo "existente", según 
los valores que una cultura le asigna y que, al mismo tiempo permiten y ordenan su funcionamiento. De esta manera, el discurso es el lugar donde se articulan el sentido y los funcionamientos socioculturales. (Callegaro, Di Leo Razuk, \& Mizrahi, 2017, p. 19)

\section{Posibles conclusiones (deducciones pedagógicas) de la reconstrucción del mundo-interfaz}

Ante una realidad dirigida desde una perspectiva ideológica y política cabe cuestionarse cómo deconstruir el relato, cómo incidir en esa interfaz, cómo desarticular la hegemonía - en términos gramscianos- detentada por una plutocracia mediática. La clave está en el propio análisis efectuado sobre la naturaleza plural de la mirada. La acción de lo visible, lo visual y lo imaginario depende de la colectividad, la construcción simbólica siempre será colectiva, teniendo en cuenta que si no construimos nosotros la realidad, la construyen otros por nosotros, articulándonos e imponiendo certezas y subjetividades. Hoy vivimos en la certeza impuesta de que no podemos variar nuestra realidad. Y la propia sustancia de un hecho cultural lo contradice: la realidad (la interfaz-mundo) podemos subvertirla porque está en su propia naturaleza cultural. Este hecho teórico es deducido de la práctica del poder en términos macrocontextuales, pero también de la aplicación en microcontextos como comunidades o familias, y la historia de la antropología, en sus diferentes tradiciones culturales, lo pone en evidencia. Sin embargo, articular estrategias audiovisuales que contrarresten los discursos mediáticos hegemónicos es una empresa titánica con un claro ejercicio de contrapoder, pero por definición del término no es imposible de llevar a cabo, aunque pasará inevitablemente por dos canales de acción prioritarios:

En primer lugar, la implementación de un cambio de marco conceptual de referencia. George Lakoff (2007) definía a los marcos de referencia como inaudibles e invisibles, pero habitan entre nuestras estructuras intersticiales del pensamiento, atravesándolo en su totalidad: "Forman parte de lo que los científicos cognitivos llaman el «inconsciente cognitivo» - estructuras de nuestro cerebro a las que no podemos acceder conscientemente, pero que conocemos por sus consecuencias: nuestro modo de razonar y lo que se entiende por sentido común" (p.4). Y aunque Lakoff centraba su estudio en los marcos lingüísticos, su extrapolación semiótica a la imagen es igualmente válida, así como todas las palabras se definen en relación a marcos conceptuales, cuando están vehiculizadas a su vez a través del audiovisual, su repercusión se expande, no solo oír una palabra activa en el cerebro su marco o colección de marcos, cuando se acompaña de una imagen su efecto se amplifica por el uso de diferentes dimensiones, sonora y visual. Para influir en nuestra realidad y reconfigurarla es necesario cambiar de marco conceptual y orientar hacia ese objetivo una acción política de cambio: "Cambiar de marco es cambiar el modo que tiene la gente de ver el mundo. Es cambiar lo que se entiende por sentido común. Puesto que el lenguaje activa los marcos, los nuevos marcos requieren un nuevo 
lenguaje. Pensar de modo diferente requiere hablar de modo diferente" (Lakoff, 2007, p. 4). Pensar de modo diferente requiere mirar de modo diferente.

En segundo lugar, otro canal de acción es esencialmente el desarrollo de una perspectiva crítica de la educación. Combatir la manipulación y hegemonía mediática necesita de un cambio de marco conceptual, y este cambio de marco de referencia es un trabajo eminentemente educacional: el contexto educativo debe tomar conciencia de la necesidad de implicarse en la transformación social e ir más allá de ejercer de correa de transmisión jerárquica donde el maestro informa sobre un supuesto saber a su estudiantado. La educación es más que una preparación técnica que dota de herramientas a un alumnado que deberá adaptarse al mundo que es dirigido por otros, al que no podemos acercarnos con una actitud neutral y donde los distintos productores mediáticos construyen versiones diferentes de este mundo, poniéndolas a consideración de un público (Ferguson, 2007). Se trata entonces de trascender y transformar los espacios educativos que abogan por la adaptación de herramientas para la perpetuación del marco referencial conceptual y la infraestructura social de la realidad presente; espacios educativos que socavan la solidaridad y permanecen orientados a la competencia, a valores asociados al laissez faire y a la flexibilización laboral, al sálvese quien pueda y al self-made man, conceptos vinculados a la gubernamentalidad neoliberal vigente y a las leyes que articulan políticamente la interfaz que hoy nos cubre. La perspectiva crítica de la educación propone una metamorfosis sistémica, un cuestionamiento del para qué y para quién educamos (Freire, 2007), desdeñando la finalidad de la mera adaptación, y manteniendo como objetivo una transformación de este mundo. Y para ello, si pensar de modo diferente requiere mirar de modo diferente, hay que radicalizar el razonamiento yendo a la base legitimadora, es decir, comprender y comprometerse con ese cambio ético (y también estético) de perspectiva educativa: permutar transmisión informativa y adaptación al contexto por transformación social. Dentro de un enfoque pedagógico crítico, basándonos en el pensamiento de Giroux (2003) en torno al cine - el cual podemos hacerlo extensible al resto de audiovisuales-, a través de mismo se pone en juego problemas que conciernen al discurso público, al debate y a la manera de hacer política de modo diverso, ubicado estratégicamente entre el reino privatizado del hogar y otras esferas públicas, así, los audiovisuales proporcionan un espacio distinto en el que un conjunto de problemas y significados contradictorios entran en un discurso público tratando problemas urgentes, acuciantes y profundos; por otro lado, el audiovisual tiende puentes entre los discursos públicos y privados, ofreciendo un contexto pedagógico, desde la crítica, la lectura - en sus diferentes variables de código, texto y contexto (Gombrich, 1987)—- pero también, y por supuesto, la creación, para armar la visión que la sociedad tiene de sí misma y del mundo del poder, los acontecimientos y la política. Este cambio social pasa por la ciudadanía y por la institución. En otras palabras, el cambio social pasa por las aulas. 


\section{Referencias}

Arnheim, R. (1986). El pensamiento visual. Barcelona: Paidós.

Aumont, J. (1992). La imagen. Barcelona: Aumont.

Berger, J. (2017). Modos de ver. Barcelona: Gustavo Gilli.

Buñuel, L. (Dirección). (1929). Un perro andaluz [Película].

Callegaro, A., Di Leo Razuk, A., \& Mizrahi, E. (2017). Cine y cambio social. San Justo: Clacso.

Debord, G. (2000). La sociedad del espectáculo. Valencia: Pre-Textos.

Eagleton, T. (1997). Ideología: una introducción. Barcelona: Paidós.

Ferguson, R. (2007). Los medios bajo sospecha. Ideología y poder en los medios de comunicación. Barcelona: Gedisa.

Freire, P. (2007). Pedagogía del Oprimido. Madrid: Siglo XXI.

Giroux, H. (2003). Cine y entretenimiento. Elementos para una crítica política del filme. Barcelona: Paidós.

Gombrich, E. H. (1987). La imagen y el ojo. Madrid: Alianza.

Goodman, N. (2013). Maneras de hacer mundos. Madrid: La Balsa de Medusa.

Lakoff, G. (2007). No pienses en un elefante. Lenguaje y debate político. Madrid: Complutense.

Mettz, C. (1972). Más allá de la analogía, la imagen. En C. Metz, U. Eco, J. Durand, G. Péninou, V. Morin, S. Du Pasquier, . . . J.-L. Schefer, Análisis de las imágenes (pp. 9-22). Buenos Aires: Tiempo Contemporáneo.

Orwell, G. (1980). 1984. Barcelona: Salvat Editores.

Scott, R. (Dirección). (1982). Blade Runner [Película].

Thompson, J. B. (1984). Studies in the Theory of Ideology. Cambridge: John Wiley $\&$ Sons. 